\title{
CONTRIBUIÇÕES DE UMA PROPOSTA INTEGRADORA EM CURSOS DE LICENCIATURA: A VISÃO DOS PROFESSORES FORMADORES
}

\section{CONTRIBUTIONS OF AN INTEGRATIVE PROPOSAL IN LICENCIATURE COURSES: THE TEACHER TRAINERS' VISION}

\author{
VOIGT, Jane Mery Richter \\ jane.mery@univille.br \\ UNIVILLE - Universidade da Região de Joinville \\ PESCE, Marly Krüger \\ marly.kruger@univille.br \\ UNIVILLE - Universidade da Região de Joinville \\ GARCIA, Berenice Rocha Zabbot \\ bgarcia@univille.br \\ UNIVILLE - Universidade da Região de Joinville
}

\begin{abstract}
RESUMO O objetivo deste artigo é discutir como professores de uma Instituição de Ensino Superior, que atuam numa proposta denominada Núcleo Pedagógico Integrador - NPI percebem sua atuação e significam sua experiência na formação de professores. Os dados da pesquisa, de abordagem qualitativa, foram coletados por meio de um questionário com perguntas abertas e fechadas. Os respondentes foram os professores que atuavam nas disciplinas do NPI em 2014. Os resultados apontam que como os professores precisam trabalhar com turmas de licenciandos de diferentes áreas de conhecimento ao mesmo tempo, reconhecem a necessidade de rever sua prática, considerando princípios como a diversidade de pensamento e o trabalho coletivo.
\end{abstract}

Palavras-chave: Formação de Professores. Práticas Educativas. Proposta Integradora.

ABSTRACT The aim of this article is to discuss how teachers of a university who work in a teaching education proposal named Integrative Pedagogic Core - IPC, realize their performance and signify their experience in teacher education. The research has a qualitative approach. The data were collected through a questionnaire with open and closed questions. The respondents were teachers who worked in IPC disciplines in 2014. The results show that as the teachers have to work with group of students from different areas of knowledge at the same time, they recognize the necessity to review their practice considering principles as diversity of thought and collective work.

Keywords: Teacher training education. Educational practices. Integrative Proposal. 


\section{INTRODUÇÃO}

Para atuar na educação básica, os professores, como profissionais da educação, devem ter formação superior, uma exigência legal, reafirmada no Plano Nacional de Educação - PNE (BRASIL, 2014), que pode ser evidenciada em sua quinquagésima meta:

Garantir, em regime de colaboração entre a União, os Estados, o Distrito Federal e os Municípios, no prazo de 1 (um) ano de vigência deste PNE, política nacional de formação dos profissionais da educação de que tratam os incisos I, II e III do caput do art. 61 da Lei no 9.394, de 20 de dezembro de 1996, assegurado que todos os professores e as professoras da educação básica possuam formação específica de nível superior, obtida em curso de licenciatura na área de conhecimento em que atuam.

A atividade docente deve ser exercida por um profissional com formação acadêmica específica para o magistério, sendo, portanto, a licenciatura um requisito indispensável. Para além da exigência, almeja-se que as Instituições de Ensino Superior - IES também se preocupem em ofertar cursos de licenciatura cujos currículos garantam a formação inicial plena, que contemplem o conhecimento científico aprofundado na área específica e na área pedagógica, além de uma sólida formação humana e cultural, articulada com outros níveis de ensino e instâncias competentes, criando ambientes de interdisciplinaridade.

Os desafios encontrados na escola de educação básica fazem com que as instituições formadoras de professores apresentem novas propostas curriculares. Nesta perspectiva, uma universidade comunitária da região sul do Brasil reestruturou seus cursos de licenciatura. A proposta delineou um perfil profissiográfico comum a todos os cursos oferecidos pela universidade no que se refere à formação para a docência, o que foi contemplado em todos os Projetos Pedagógicos dos Cursos de Licenciatura. O referido perfil indica que o egresso dos cursos de Licenciatura seja capaz de desempenhar a função de educador, fundamentado em uma sólida formação humanística em que a ética, a cidadania e o compromisso com a diversidade, o meio ambiente, e com o ensino e aprendizagem, sejam os parâmetros do seu trabalho; interferir no contexto social por meio da proposição e implementação de alternativas teórico-práticas no seu campo de atuação; utilizar, de forma ética e 
humanística, os conhecimentos científicos e os recursos proporcionados pelos avanços tecnológicos.

Para contribuir com o desenvolvimento desse perfil foi criado o Núcleo Pedagógico Integrador - NPI que é constituído pelas disciplinas: Filosofia, Metodologia da Pesquisa em Educação, Psicologia da Educação, Didática, História da Educação, Diversidade em Educação e Inclusão, Políticas Públicas e Gestão Escolar, Libras e Códigos de Comunicação.

Essas disciplinas são distribuídas ao longo da matriz dos cursos, sendo que os estudantes oriundos dos vários cursos de licenciatura frequentam as aulas numa mesma turma de, no máximo, cinquenta alunos. Dessa forma, eles têm a oportunidade de, ao cursar disciplinas do NPI com colegas de outras áreas do conhecimento, realizar trabalhos interdisciplinares e dialogar com outros saberes para além da especificidade de sua área de formação. Esta situação se apresenta desafiadora para o professor formador, tendo em vista que sua experiência tem sido lecionar apenas para turmas com estudantes da mesma área presentes na sala de aula.

Diante dos desafios dos professores formadores que atuam nessa instituição de ensino superior, o objetivo deste artigo é apresentar os resultados de uma pesquisa que investigou como os professores que atuam no NPI compreendem/significam a proposta integradora.

\section{FUNDAMENTAÇÃO TEÓRICA}

O ato de ensinar se constitui na relação dos sujeitos envolvidos com a aquisição do conhecimento, e é, segundo Tardif e Lessard (2005, p.8) "[...] uma forma particular de trabalho sobre o humano, ou seja, uma atividade em que o trabalhador se dedica ao seu 'objeto' de trabalho, que é justamente outro ser humano, no modo fundamental da interação humana". Nesse sentido, o exercício da docência leva à transformação dos sujeitos participantes do processo de ensino aprendizagem.

Ao considerarmos que a tarefa do professor é ensinar, devemos levar em conta o conceito do que é ensinar. Para exercer com propriedade sua tarefa, o professor deve conhecer muito bem o conteúdo da disciplina que leciona, além de dominar os saberes do campo da educação. Esses saberes habilitam-no a desenvolver sua atividade objetivando a aprendizagem do aluno e não simplesmente a transmissão do conteúdo. Ou seja, ensinar é uma ação cognoscível e deliberada que o professor deve 
Atos de Pesquisa em Educação - ISSN 1809-0354

ter para mobilizar e mediar a aprendizagem de um conteúdo do qual o aluno deve apropriar-se, sendo esta ação específica desse profissional que precisa ser reconhecido por sua ação docente e por seu papel na sociedade.

Tardif (2011) destaca que o professor não trabalha com objetos, mas com pessoas, por isso o seu trabalho é de cunho social e ensinar é agir com outros seres humanos, numa relação em que se conhecem os papéis específicos de cada um: o de ensinar e o de aprender. A tarefa de ensinar requer saberes específicos da docência sendo eles: os saberes da formação profissional, os saberes disciplinares, os saberes curriculares e os saberes experienciais.

Os saberes da formação profissional são provenientes do conhecimento a respeito das ciências da educação e de métodos e técnicas pedagógicas os quais são estudados e apreendidos em instituições de formação inicial. Os disciplinares consistem no domínio do conhecimento específico das diversas áreas a serem ensinadas. Os saberes curriculares correspondem aos discursos, objetivos, conteúdos e métodos (programas escolares) trabalhados nas instituições de ensino. A tarefa diária de ensinar e o conhecimento do professor sobre o meio em que está inserido produz saberes experienciais ou saberes da prática docente, esses brotam da experiência e por ela são validados.

Tardif (2011, p. 39) afirma que os saberes não são lineares nem hierárquicos, mas são elementos constitutivos da prática docente dos professores e que:

\footnotetext{
Essa dimensão da profissão docente lhe confere o status de prática erudita que se articula, simultaneamente, com diferentes saberes: os saberes sociais, transformados em saberes escolares, através dos saberes disciplinares e dos saberes curriculares, os saberes oriundos das ciências da educação, os saberes pedagógicos e os saberes experienciais. Em suma 0 professor ideal é alguém deve conhecer sua matéria, sua disciplina, e seu programa, além de possuir certos conhecimentos relativos às ciências da educação e a pedagogia e desenvolver um saber prático baseado em sua experiência no cotidiano com os alunos.
}

Considerando que há saberes necessários para a atuação docente e um dos espaços no qual se constituem esses saberes são os cursos de licenciatura, é necessário destacar que, a formação inicial deve, entre outros aspectos, fornecer bases para a construção de um conhecimento pedagógico especializado, oferecendo conhecimentos necessários que sejam válidos e que gerem uma atitude interativa e dialética. Esta formação deve ainda apresentar um currículo formativo que provoque 
experiências interdisciplinares que deem condições ao futuro docente para integrar os conhecimentos didáticos aos conhecimentos psicopedagógicos. Porém, os cursos de formação inicial de professores parecem não dar conta do princípio dialético constitutivo da docência (IMBERNÓN, 2011).

Segundo Gatti (2009), os baixos níveis de aprendizagem escolar do nosso país apontam à necessidade de se rever as condições de oferta dos cursos de licenciatura tanto no que se refere às estruturas institucionais quanto aos seus currículos e conteúdos formativos.

Nessa perspectiva, as propostas dos cursos de licenciatura precisam incorporar práticas pedagógicas que levem o futuro professor a desenvolver atividades que ajudem o seu aluno a desenvolver-se como pessoa. Formosinho (2009, p. 107) entende que "a assunção de uma cultura profissional de formação pressupõe considerar os estudantes, para além de alunos de disciplinas curriculares, como futuros ou potenciais professores, o que implica propor-lhes diferentes estratégias de aprendizagem."

Pesquisadoras como Martins e Romanowski (2010), ao analisar produções acadêmicas sobre a situação atual das licenciaturas, ratificam que as diretrizes para os cursos de licenciatura (BRASIL, 2002) desencadearam, tanto em instituições públicas como privadas, processos de reformulação dos cursos, porém elas continuam centradas na formação técnica, sem superação da fragmentação da teoria e da prática, do conteúdo e do método. Como esta racionalidade apresenta-se configurada por uma nova epistemologia da prática, que tem a reflexão e a investigação como motriz da aprendizagem do ofício, gera um embate quanto à concepção de formação docente. As autoras exemplificam que há diferentes conflitos nos cursos centrados nos conteúdos específicos, nos que procuram imprimir à docência uma identidade própria, nos que confirmam a formação centrada nas competências.

As propostas de reformulação dos cursos de formação tentam partir de uma crítica ao modelo da racionalidade técnica, uma atividade instrumental utilizada na solução de problemas mediante a aplicação de teorias e técnicas (PÉREZ GÓMES, 1995). Contreras (2002) compreende que o modelo de formação com base na racionalidade técnica é regulado por um sistema lógico e infalível de procedimentos, constituído a partir de um conjunto de premissas. Esta lógica não permite que se 
Atos de Pesquisa em Educação - ISSN 1809-0354

Blumenau - vol. 11, n. 2, p.532-548 ago./nov. 2016

DOI: http://dx.doi.org/10.7867/1809-0354.2016v11n2p532-548

considere o imprevisível e a incerteza que é próprio da realidade em sala de aula. Assim, entra em discussão qual professor pretende-se formar. Gatti e André (2010) ressaltam que a docência deve ser exercida por profissionais que:

[...] enfeixam a racionalização dos conhecimentos e habilidades necessárias ao exercício profissional, e que a profissionalização de professores implica a obtenção de um espaço autônomo, próprio à sua profissionalidade, com valor claramente reconhecido pela sociedade. Não há consistência em uma profissionalização sem a constituição de uma base sólida de conhecimentos e formas de ação (RAMALHO, NUÑEZ E GAUTHIER, 2003 apud GATTI e ANDRÉ, 2010, p. 1359).

Propostas inovadoras, como a dos cursos de licenciatura da IES pesquisada, podem representar um salto qualitativo para a formação docente com vistas a preparar um profissional capaz de enfrentar os desafios emergentes no contexto escolar e de solucionar os problemas de aprendizagem dos alunos, subsidiado pelo conhecimento teórico metodológico estudado durante o curso de graduação. Todavia, segundo Gatti e André (2010, p. 1359), "[...] qualquer inovação na estrutura de instituições e cursos formadores de professores esbarra na representação tradicional e nos interesses instituídos, o que tem dificultado repensar e reestruturar essa formação de modo mais integrado e em novas bases." Dessa forma, a implantação de uma proposta inovadora precisa levar em conta o corpo docente que irá colocá-la em prática. Há necessidade de se estabelecer uma formação continuada para esses professores e condições para que possam discutir e planejar juntos as atividades pedagógicas. A experiência de compartilhar poderá ajudar o professor formador a desenvolver com mais propriedade as atividades interdisciplinares.

Já na década de 1970, Japiassú (1976) argumentava que interdisciplinaridade passou a existir como uma necessidade atribuída pela manifestação de aplicação de novas disciplinas. É indispensável que exista um acordo entre as disciplinas, explicitando as dependências entre elas. Para Fazenda (2006, p.89), interdisciplinaridade "não é apenas uma categoria de conhecimento, mas de ação". As práticas interdisciplinares propiciam uma melhora no desenvolvimento da própria disciplina ou da área do conhecimento, na tolerância à dúvida, na desenvoltura para sintetizar ou ampliar horizontes, no aumento do pensamento criativo, original e nãoconvencional e no aumento da aptidão de escutar pontos de vistas distintos e sensibilidade para ideias oblíquas (FAZENDA, 2002). 
Ao se optar pelo conceito de interdisciplinaridade na formação de professores como atitude inovadora para a construção do conhecimento, deve-se considerar a cultura e as condições da instituição formadora. Fourez (2001, apud FAZENDA, 2009) destaca duas ordenações ao se referir à formação interdisciplinar de professores: a ordenação científica e a ordenação social.

A ordenação científica representa a organização dos saberes do conhecimento científico da formação de professores. Nesse sentido, as disciplinas didáticopedagógicas, neste caso do $\mathrm{NPI}$, devem contemplar os fundamentos teóricos e metodológicos próprios de sua cientificidade, a qual pode adquirir status interdisciplinar quando o professor revê as suas práticas.

A ordenação social implica considerar os saberes científicos interdisciplinares numa perspectiva de demandas sociais, ou seja, a formação docente deve proporcionar a superação da dicotomia entre teoria e prática, considerando as condições sociais e históricas das práticas dos professores.

Tardif (2011, p. 36) define o saber docente como "um saber plural, formado pelo amálgama, mais ou menos coerente, de saberes oriundos da formação profissional e de saberes disciplinares, curriculares e experienciais." Ele afirma que o professor, em sua prática cotidiana, apoia-se em sua experiência e faz uso de seus conhecimentos pessoais na construção de um saber-fazer personalizado, que dê conta de suas múltiplas atribuições.

O autor chama a atenção para a natureza social do saber profissional, considerando que:

[...] os diversos saberes dos professores estão longe de serem todos produzidos diretamente por eles, e muitos deles são de certo modo 'exteriores' ao ofício de ensinar, pois provém de lugares sociais anteriores à carreira propriamente dita, ou estão situados fora do trabalho cotidiano (TARDIF, 2011, p. 64).

As atividades interdisciplinares representam um avanço na qualificação do trabalho docente, por constituírem-se em oportunidades no que se refere às experiências de convívio com diferentes perspectivas técnicas e científicas e diferentes conjuntos de valores, mesmo que haja, ainda, dificuldades na compreensão do conceito de interdisciplinaridade e de sua efetivação no cotidiano dos cursos de formação de professores. 


\section{PERCURSO METODOLÓGICO}

De abordagem qualitativa, a pesquisa a qual se refere esse artigo, compreende o homem como um ser social que se constitui pela atividade mediada pela linguagem, ratificando seu caráter sócio histórico.

Nessa perspectiva, fazer uso deste tipo de abordagem é investigar opiniões, percepções, representações, sentimentos, centrando-se na visão do sujeito e no objetivo do que se está investigando. Fazer uso da metodologia de pesquisa qualitativa não exclui a possibilidade da utilização de dados quantitativos, como também é o caso desta pesquisa, conjugando/integrando informações para construir a análise dos dados obtidos durante a investigação (GATTI e ANDRÉ, 2010).

Ao fazer uma pesquisa que utiliza dados quantitativos, na análise estará presente o quadro de referência do pesquisador, seus valores, sua visão de mundo, que são marcas da subjetividade e que caracteriza a dimensão qualitativa (ANDRÉ, 2007).

Esta pesquisa foi realizada em uma universidade comunitária da região sul do Brasil, que oferece cursos de formação de professores presenciais há cerca de cinquenta anos. Foram sujeitos dessa pesquisa os professores que atuam nas disciplinas do NPI dos cursos de licenciatura oferecidos pela instituição: Artes Visuais, Ciências Biológicas, Educação Física, História, Letras e Pedagogia. No período letivo de realização da pesquisa, em 2014, dezoito professores lecionavam nas diversas disciplinas que constituem o NPI, sendo que onze responderam ao questionário.

Para coletar os dados foi aplicado um questionário com perguntas abertas e fechadas. Nesse artigo, foram utilizadas as questões relacionadas à identificação do respondente a fim de caracterizar o perfil do professor formador e sua experiência na Educação Básica. Também foram descritas questões que deixaram evidente quais as contribuições da proposta integradora para a formação dos licenciandos.

A análise dos dados levou em conta as exigências necessárias à atuação em disciplinas pedagógicas e fez uso dos referenciais teóricos pertinentes à área da educação. As respostas foram tabuladas a fim de relacionar e identificar uma tendência dos aspectos que caracterizam os sujeitos e também suas percepções sobre o objeto de pesquisa.

\section{DISCUSSÃO DOS RESULTADOS}


Atos de Pesquisa em Educação - ISSN 1809-0354

Para atuar numa proposta diferenciada em que os projetos pedagógicos dos cursos de licenciatura indicam um perfil profissiográfico comum ao que se refere à formação docente é necessário que o professor formador apreenda a concepção delineada no projeto a fim de se sentir coparticipante do processo de mudança.

Compreender como ocorre a mudança na prática do professor formador nesse cenário, levou-nos a investigar a compreensão dos sujeitos sobre a sua atuação no NPI. A análise foi feita com base nos resultados sobre o perfil dos professores participantes da pesquisa, sobre a percepção de como foi lecionar disciplinas de conhecimento pedagógico para turmas com alunos de diversos cursos, sobre como os professores formadores perceberam que a construção das atividades pedagógicas transcende a lógica da racionalidade técnica e, sobre a visão acerca da contribuição da proposta integradora para a formação docente.

Quanto à formação, verificou-se que cinco professores têm como titulação máxima doutorado, cinco são mestres e um professor especialista. A maioria apresenta formação em nível de pós-graduação stricto senso o que qualifica o corpo docente.

A titulação é um fator relevante, pois o professor formador deve ter profundo conhecimento sobre os conteúdos teóricos e metodológicos da disciplina que leciona para poder mediar com propriedade a aprendizagem dos alunos. Para Shulman (1994), o conhecimento sobre a área de atuação repousa em dois fundamentos: a literatura acumulada e os estudos nas áreas e o conhecimento filosófico e histórico sobre a natureza desse conhecimento. Esses conhecimentos possibilitam ao professor:

[...] enfrentar a diversidade dos alunos, o professor deve ter a flexibilidade e a compreensão multifacetada, adequada para conceder explicações alternativas dos mesmos conceitos e princípios. O professor também comunica, conscientemente ou não, ideias sobre os modos pelos quais "a verdade" é determinada em uma área e um conjunto de atitudes e valores que, de forma marcante, influencia o entendimento do aluno. Esta responsabilidade exige especialmente da profundidade do próprio professor de entender as estruturas da disciplina, bem como das atitudes do professor e seu entusiasmo por aquilo que está sendo ensinado e aprendido. Estes muitos aspectos do conhecimento do conteúdo, conseqüentemente, são apropriadamente entendidos como característica central da base do conhecimento do ensino (SHULMAN,1994, p. 8). 
respondentes é de mais de cinco anos: três professores atuaram mais de cinco anos; três até vinte anos e outros três mais de vinte anos, o que demonstra um percurso significativo desses professores nesse nível de ensino. Embora o número de anos por si só não represente uma relação direta com a qualidade de sua forma de ensinar, o conhecimento sobre o campo de trabalho, no qual os estudantes irão atuar, auxilia na contexualização dos conteúdos a serem abordados nas aulas. A experiência em escolas de Educação Básica constitui os saberes experienciais desses professores, o que pode ajudar na proposição dos conteúdos estudados na formação inicial.

Há uma exigência legal para que parte dos professores dos cursos de licenciatura tenha atuado na Educação Básica, o que é atendido pelos professores do NPI, pois nove dos professores respondentes disseram ter experiência nesse nível de ensino e apenas dois não.

Os saberes da experiência são constituídos durante a intervenção pedagógica do professor na escola e na organização do trabalho pedagógico. Para Tardif (2011), esses saberes não se originam nas instituições formadoras nem se encontram nos currículos dos cursos de licenciatura, muito menos estão sistematizados em teorias, pois eles são produzidos pelo próprio professor durante seu percuso profissional, sendo ele, ao mesmo tempo, produtor e sujeito desses saberes.

Quanto ao nível em que os professores atuaram na Educação Básica, apenas três o fizeram na educação infantil, os demais no ensino fundamental e médio. A experiência nos diferentes níveis da Educação Básica pode ajudar o grupo de professores a exemplificar e estabelecer relações entre os conteúdos abordados. A relação teoria e prática pode ser efetivada se o professor tiver repertório para tal. Para o estudante da licenciatura é uma oportunidade ímpar na formação, ter a possibilidade de ouvir professores com experiências diversas.

Diante do exposto, concordamos com Imbernón (2011) que o desenvolvimento do conhecimento profissional do professor deve ser fomentado por processos reflexivos sobre a educação e a realidade educacional, e assim,

[...] se a formação deve ser direcionada para o desenvolvimento e consolidação de um pensamento educativo, incluindo os processos cognitivos e afetivos que incidem na prática dos professores, esse pensamento educativo deve ser o produto de uma práxis, uma vez que no decorrer do processo não apenas se ensina, mas também se aprende (IMBERNÓN, 2011, p.66). 
O perfil dos professores investigados mostra que eles possuem titulação adequada para atuar em cursos de licenciatura, têm experiência na Educação Básica em todos os níveis de ensino, o que constitui fonte de vivências que permitem reflexões e a relação teoria e prática.

$\mathrm{Na}$ questão relacionada à percepção de como foi lecionar disciplinas de conhecimento pedagógico para turmas com alunos de diversos cursos, os professores puderam assinalar mais de uma alternativa. Seis professores consideraram a tarefa desafiadora, devido à necessidade de contemplar as diversas áreas de formação em um mesmo momento. Quatro professores consideraram árdua a tarefa, pois o planejamento das aulas exige a escolha de estratégias para trabalhar com grupos numerosos e diversificados. Apenas um dos professores demonstrou indiferença, considerando que os conteúdos que leciona são genéricos ou gerais, assim o fato de trabalhar com alunos de diferentes licenciaturas não interfere em seu trabalho. Do grupo pesquisado, quatro professores consideraram gratificante, pois entendem que a integração de alunos de diferentes cursos de licenciatura foi uma ótima oportunidade de crescimento.

Os respondentes consideram uma experiência desafiadora e árdua trabalhar no NPI, pois exige uma mudança na prática pedagógica. Perante a necessidade de mudança os professores se sentem ao mesmo tempo desafiados e ameaçados (FAZENDA, 2009). Novas situações que se apresentam no cotidiano podem fazer com que o professor questione sua maneira de atuar, deixando-o inseguro.

A experiência de trabalhar com alunos de diferentes cursos de licenciatura já ocorreu em outras instituições formadoras, como, por exemplo, a experiência de Pimenta (2001), que relata a relevância de suas atividades com acadêmicos de diferentes cursos de licenciatura nas aulas de Didática, em que o desafio é trabalhar coletivamente, conviver com diferentes linguagens, discursos e saberes dos acadêmicos. Ela destaca que esta convivência é uma oportunidade de se construir a identidade do professor, inclusive, porque na escola também deverão atuar e interagir com profissionais de diferentes áreas. A diferença dessa experiência e da proposta investigada está no fato de a integração ter como objetivo um perfil profissiográfico comum aos licenciandos e que está contemplado no projeto pedagógico de cada curso e ao longo da matriz curricular. 
Outra questão proposta visava identificar como os professores percebem que a suas práticas pedagógicas podem transcender a lógica da racionalidade técnica, que é regulada por um sistema lógico e infalível de procedimentos e que não considera a imprevisibilidade da realidade e a visão dos sujeitos (CONTRERAS, 2002). Sete respondentes indicaram que o professor formador deve aumentar a aptidão de escutar pontos de vista distintos, quatro sugerem adotar uma atitude que busque um espaço de coesão entre diferentes conhecimentos e dois professores consideraram importante perceber as diferentes visões das áreas de formação dos estudantes.

A interdisciplinaridade, para a maioria dos professores respondentes, é uma forma de romper com o modelo dos cursos de licenciatura baseado na racionalidade técnica. Para os respondentes, a formação docente não pode ser regulada por um sistema lógico e infalível de procedimentos que, segundo Contreras (2002), se constitui a partir de um conjunto de premissas, mas deve ser fundamentada em princípios que tornem as disciplinas comunicáveis entre si e concebendo-as como processos históricos e culturais. As professoras formadoras percebem a sua atuação no NPI como uma possibilidade de superar a visão restrita da realidade que pode ocorrer quando da fragmentação do conhecimento nas disciplinas.

Para identificar a visão dos professores sobre a contribuição da proposta integradora para a formação docente, foi elaborada uma questão aberta, cujas respostas serão discutidas a seguir.

Nas falas dos sujeitos podemos observar que os professores identificam contribuições da proposta integradora. No excerto "enfrentar a complexidade da realidade atual" (P1), pode-se evidenciar a visão do professor de que a realidade não é linear. A oportunidade de atuar no NPI, favorece a vivência de significar o conceito de complexidade.

Para Morin (2007), o pensamento linear revela-se nas tentativas de aplicar aos problemas divergentes suposições simplistas de causa e efeito. Já a visão de que a realidade é complexa significa compreender as coisas, considerando os processos numa relação dialógica. A complexidade pressupõe uma interação permeada por várias partes que constituem o todo, o qual é maior que a soma das partes isoladas. A interação entre as partes detém a capacidade de transformar o todo e a si mesmas.

Percebe-se novamente o paradigma da ciência pós-moderna, em falas dos professores participantes da pesquisa como "o respeito à diversidade de pensamento" 
(P2). Morin (2004) entende que um dos saberes necessários à educação é o de ensinar para a compreensão, cujo objetivo é levar o estudante a compreender o outro, respeitando suas ideias e seu modo de viver.

Estes pressupostos fundamentam os documentos institucionais como a Proposta Pedagógica Institucional e a Proposta Pedagógica dos Cursos, também está presente no programa de profissionalização docente da IES, o que pode ter constituído a identidade do professor formador que atua no NPI. Também é possível considerar que as disciplinas pedagógicas favorecem a discussão de temas pertinentes ao fazer docente e esses pressupostos podem dar conta da complexidade da prática pedagógica da sala de aula.

Outra questão apontada pelos professores é a importância da construção de conhecimento elaborada juntamente com outros docentes. Na fala de P3, "entender que as discussões de diferentes idéias compõem o universo de uma equipe de trabalho numa escola, que é este trabalho que forma o coletivo", percebe-se que o professor formador deixa evidente que na escola o futuro licenciando irá encontrar colegas professores de diferentes áreas com os quais terá a oportunidade de compartilhar conhecimentos. O professor formador também vivencia o trabalho coletivo considerando as ideias das diferentes áreas do conhecimento ao ministrar aulas em turmas com alunos de diversos cursos.

É essencial oportunizar a experiência do trabalho coletivo no curso de formação inicial, porém a formação para a docência não é única e não ocorre apenas na instituição formadora. Há saberes, como o experiencial, que são constituídos na escola e na relação com o outro, especialmente com o colega de profissão. Para a Cochran-Smith e Lytle (1999), os professores aprendem quando geram conhecimento local, refletindo sobre a prática pedagógica e teorizando e construindo seu trabalho de forma a conectá-lo às questões sociais, culturais e políticas mais gerais.

Outros autores que trabalham com a noção de saberes necessários à docência, como Pimenta (1999) e Tardif (2011), postulam que os professores reelaboram estes saberes nas experiências vividas no contexto escolas num processo coletivo de troca entre com os colegas docentes. A reflexão na prática e sobre a prática permite que o professor reelabore os saberes necessários ao exercício profissional. Portanto, os professores ressignificam os conhecimentos/saberes aprendidos na graduação em confronto com os do cotidiano da sala de aula e da escola. A oportunidade de 
confrontar o cotidiano da escola já durante a formação inicial, além do estágio, para alguns professores participantes da pesquisa o NPI também parece contribuir para que o licenciando tenha uma vivência do que encontrará na vida profissional.

Pode-se perceber que a maioria dos professores formadores atuaram ou atuam na Educação Básica, o que pode fazer com que esse profissional compreenda a importância dos saberes experenciais.

Considerando a resposta do professor P4:

"Minha opinião é que frequentar disciplinas junto, não garante nada. É como frequentar a sala dos professores da escola com professores de todas as áreas. A diferença está na mediação do diálogo e nos desafios para resolução de problemas" (P4).

Nesta perspectiva, apenas reunir alunos de diferentes licenciaturas não garante uma integração entre as áreas, mas pode ser um espaço privilegiado para novas mediações. Assim, o professor do NPI precisa planejar suas aulas considerando procedimentos metodológicos que promovam a integração dos alunos dos diversos cursos e também dos diferentes conhecimentos e experiências.

Na perspectiva sócio-histórica, a categoria 'mediação' é compreendida como a possibilidade de intervenção de um elemento/um processo numa perspectiva não dicotômica e imediata, "[...] mas como elementos que, apesar de diferentes, se constituem mutuamente, possibilitando um a existência do outro numa relação de mediação" (OZELLA e AGUIAR, 2010). Dessa forma, é a mediação, o diálogo e o enfrentamento de desafios em sala de aula, no caso do NPI, ajudam a constituir sujeitos participantes do processo de forma dialética.

Na resposta do professor P5: "Trabalhar com diversidade um único assunto é muito interessante, e nos faz crescer como docente", percebe-se que o professor, ao transformar o processo de ensino-aprendizagem, transforma a si mesmo numa relação dialética com o meio. Bock (1999), com base em Marx, ressalta que este processo ocorre porque a atividade do homem é definida pela forma com que a sociedade se organiza para o trabalho, considerando-o um ser ativo e social. Além disso, as relações sociais modificam-se na medida em que se desenvolvem as necessidades humanas e a produção que visa satisfazê-las. E é nesse movimento, 
com base nas contradições que ocorrem as mudanças nas relações sociais, é nesse processo histórico, construído pelo homem que ele se constrói.

Há professores que discordam da forma como está organizada a proposta integradora:

"Da forma como o currículo dos cursos está sendo desenvolvido com os departamentos, ainda muito 'fechados', creio que em muito pouco contribui. Ao contrário. As dificuldades tornaram-se obstáculos à operacionalização dos objetivos das disciplinas de NPI" (P6).

A fala parece apontar para o problema de como as matrizes curriculares estão organizadas. Ao responsabilizar a instituição por não dar condição de "operacionalizar" os objetivos das disciplinas do NPI, ainda há uma visão dicotômica entre as disciplinas específicas e pedagógicas. A posição deixa claro que há um caminho a percorrer no sentido de aprimorar as relações, as práticas e as condições de trabalho dos professores formadores.

\section{CONSIDERAÇÕES}

Os professores que atuam no NPI possuem excelente titulação e uma significativa experiência nos diversos níveis da Educação Básica. Essa qualificação pode favorecer o desempenho docente no sentido de proporcionar ao licenciando oportunidade de relacionar teoria e prática, considerando a realidade que irá encontrar na escola (GATTI, 2009).

Os professores formadores consideram uma experiência gratificante lecionar as disciplinas pertencentes ao NPI, embora ressaltem que é uma tarefa desafiadora e árdua, pois exige um cuidado maior na preparação de procedimentos didáticos que envolvam todos os estudantes.

Para os professores respondentes, a experiência de lecionar para licenciandos de diferentes àreas do conhecimento, num mesmo momento, exigiu que repensassem sua prática ao considerar os conhecimentos específicos e as características dos estudantes. Os professores também deixam evidente que a experiência contribui para os estudantes em sua formação como futuros docentes, no que se refere a compreender e respeitar a diversidade de pensamento e o contato com as diferentes visões de mundo. A vivência com colegas de diferentes áreas de conhecimento 
oportuniza/favorece a constituição identitária de um profissional mais tolerante, aberto e flexível diante dos desafios da escola.

Pode-se inferir que uma das características da cultura da profissão docente é o individualismo proporcionado pela organização curricular e pela forma como as disciplinas são distribuídas em 'grades' de horários determinados. O peso do poder individual da atividade da docência pode dificultar uma predisposição dos professores em trabalhar coletivamente. O julgamento do outro e o receio de perder o poder de decisão de suas aulas são aspectos que podem minar a adoção de uma atitude interdisciplinar pelo professor formador. Todavia, os respondentes reconhecem a necessidade de transformar sua maneira de atuar como professor formador, deixando evidente a dificuldade que têm em propor atividades que levem os estudantes a desenvolver uma atitude colaborativa e compreensiva com colegas de outras licenciaturas.

Essas primeiras análises demonstram que para se implantar uma proposta integradora e inovadora nos cursos de licenciatura é fundamental que haja um investimento na formação do professor forrmador além de proporcionar condições objetivas de trabalho e capacitações norteadoras para que haja uma mudança fundamentada e criativa na prática dos docentes.

\section{JANE MERY RICHTER VOIGT}

Doutora em Educação (PUC-SP). Mestre em Educação (UFPR). Licenciada em Matemática (FURJ). Atualmente é professora titular da Universidade da Região de Joinville-UNIVILLE, atuando em cursos de graduação e no Mestrado em Educação.

\section{MARLY KRÜGER PESCE}

Doutora em Educação (PUC-SP). Professora Titular da Universidade da Região de Joinville (UNIVILLE), atuando no Departamento de Letras e no Mestrado em Educação. Coordenadora do Centro de Inovação Pedagógica da UNIVILLE. Pesquisadora participante do grupos de pesquisa PLISA.

\section{BERENICE ROCHA ZABBOT GARCIA}

Doutora em Educação (PUC-SP). Professora Titular da Universidade da Região de Joinville (UNIVILLE), atua como professora, Chefe de Departamento do Curso de Letras e Assessora de Avaliação Institucional da UNIVILLE. Realiza estudos sobre 
Extensão Universitária e Formação de Professores e é pesquisadora participante do grupo de pesquisa PLISA.

\section{REFERÊNCIAS}

AGUIAR, W. M. J; OZELLA, S. Núcleos de significado como instrumento para a compreensão da constituição dos sentidos. Psicologia: ciência e profissão, Brasília, v. 26, n. 2, p.222-245, jun. 2006.

BOCK, A. M. B. As aventuras do Barão de Munchausen na Psicologia. São Paulo: Educ - Cortez - Fapesp, 1999, 207 p.

BRASIL/MEC. Plano Nacional de Educação - 2014 - 2024. (PNE - Lei 13.005/14). Disponível em <http://fne.mec.gov.br/images/doc/pne-2014-20241.pdf> Acesso em: 10 mar. 2015.

BRASIL/MEC. Resolução CNE/CP 01/2002, de 18 de fevereiro de 2002. Institui Diretrizes Curriculares Nacionais para a Formação de Professores da Educação Básica, em nível superior, curso de licenciatura, de graduação plena. Disponível em: $<w w w . p l a n a l t o . g o v . b r>$. Acesso em: 10 jul. 2013.

COCHRAN-SMITH, Marilyn e LYTLE, L. Susan. Relationships of Knowledge and Practice: Teacher Learning in Communities In. Sage Journals online - Review of Research in Education. January 1999. Disponível em: <http://rre.sagepub.com/content/24/1/249.full.pdf+html> Acesso em: 10 jul 2015.

CONTRERAS, J. A autonomia de professores. São Paulo: Cortez, 2002, 296 p.

FAZENDA, I. C. A. Formação de Professores: dimensão interdisciplinar In: Revista Brasileira de Formação de Professores - RBFP - Vol. 1, n. 1, p.103-109, Maio/2009.

FAZENDA, I. C. A. (Org.). Interdisciplinaridade na educação brasileira: 20 anos. São Paulo: Criarp, 2006, 224 p.

FAZENDA, Ivani Catarina Arantes. Reflexões metodológicas sobre a tese:"interdisciplinaridade: um projeto em parceria". In: Fazenda, Ivani Catarina Arantes. Metodologia da pesquisa educacional, v. 9, São Paulo: Cortez, p. 123-139, 2002.

FORMOSINHO. J. (org.) Formação de Professores - Aprendizagem profissional e a acção docente. Porto: Porto Editora, 2009400 p.

GATTI, B. e ANDRÉ, M. A relevância dos métodos de pesquisa qualitativa em Educação no Brasil. In: WELLER, W.; PFAFF, N. Metodologia da pesquisa qualitativa em educação: teoria e prática. Petrópolis/RJ: Vozes, 2010. P. 29-38.

GATTI, B. Formação de Professores: condições e problemas atuais. Revista Brasileira de Formação de Professores - RBFP - Vol. 1, n. 1, p.90-102, 2009. 
IMBERNÓN. F. Formação Docente e Profissional - formar-se para a mudança e a incerteza. São Paulo: Cortez, 2011, 165 p.

JAPIASSU, H. Interdisciplinaridade e patologia do saber. Rio de Janeiro: Imago, 1976, $220 \mathrm{p}$.

MORIN, Edgar. A cabeça bem-feita: repensar a reforma, reformar o pensamento. Tradução de Eloá Jacobina. 9. ed. Rio de Janeiro: Bertrand Brasil, 2004, 128 p. . Introdução ao pensamento complexo. 3. ed. Porto Alegre: Sulina, 2007, 222 p.

PÉREZ GÓMEZ, A. Formando professores como profissionais reflexivos. In: NÓVOA, António (org.) Os Professores e sua Formação. 2. ed. Lisboa, Publicações Dom Quixote, 1995. p. 77-91.

PIMENTA, S. G. Formação de professores: saberes da docência e identidade do professor. In: FAZENDA, Iv. C. A. (Org.) Didática e interdisciplinaridade. 5. ed. Campinas/SP: Papirus, 2001. p. 161-178.

MARTINS, Pura Lúcia Oliver; ROMANOWSKI, Joana Paulin. A didática na formação pedagógica de professores nas novas propostas para os cursos de licenciaturas. Convergências e tensões no campo da formação e do trabalho docente. Belo Horizonte: Autêntica, 2010, p. 61-80.

SHULMAN, L. S. Knowledge and teaching: foundations of the New Reform. In: .The Wisdom of practice: essays on teaching, learning, and learning to teach. San Francisco: Jossey-bass, 1994, 608 p.

TARDIF, M. Saberes docentes e formação profissional. 13.ed. Petrópolis/RJ:Vozes, 2011, $325 \mathrm{p}$.

TARDIF, M.; LESSARD, C. Trabalho Docente: elementos para uma teoria da docência como profissão de interações humanas. Petrópolis/RJ: Vozes, 2005, 317 p.

Artigo recebido em outubro de 2015. Aprovado em maio de 2016. 